\title{
Erratum to: An improved multimodal signal-image compression scheme with application to natural images and biomedical data
}

\author{
Tahar Brahimi $^{1}$ - Larbi Boubchir ${ }^{2}$ (D) - Régis Fournier ${ }^{3}$. \\ Amine Naït-Ali ${ }^{3}$
}

(C) Springer Science+Business Media New York 2017

\section{Erratum to: Multimed Tools Appl \\ DOI: 10.1007/s11042-016-3952-7}

In the original publication, reference citations in Figure 9 was incorrectly written as [23] and [22]. It should be written as [35] and [50]. In Figures 4, 5 and 6 "Reconstructed quantized signal" should be renamed as "Decoded quantized signal" and "Inverse 2D wavelet decomposition" found in Figs. 5 and 6 should be performed after "Image pixel interpolation." The original article was corrected.

The online version of the original article can be found at http://dx.doi.org/10.1007/s11042-016-3952-7.

\section{Larbi Boubchir}

larbi.boubchir@ai.univ-paris8.fr

Tahar Brahimi

t.brahimi@gmail.com; tbrahimi@univ-jijel.dz

Régis Fournier

rfournier@u-pec.fr

Amine Naït-Ali

naitali@u-pec.fr

1 L2EI research Laboratory, Department of Electronics, Jijel University, BP 98 Ouled Aissa, Jijel 18000, Algeria

2 LIASD research Laboratory, Department of Computer Science, University of Paris 8, 2 rue de la liberté, 93526 Saint-Denis cedex, France

3 LiSSi research Laboratory, University of Paris-Est Créteil Val-de-Marne, 61 Avenue du Général de Gaulle, 94000 Créteil, France 